\title{
A Study of College Students' Autonomous Learning Under the Mode of Distance Education
}

\author{
Liao Yidong ${ }^{1 a}$, Wei Youqiang ${ }^{2 b}$ \\ 12 Jiangxi Normal University, Nanchang, Jiangxi 330022 \\ a1021048916@qq.com, ${ }^{b} 190555223 @ q q . c o m$ \\ *Liao Yidong
}

\begin{abstract}
In today's social background, distance education provides rich learning resources and convenient learning methods for college students' autonomous learning. Under the mode of distance education, there are many problems in college students' autonomous learning, such as college students' strong dependence on teachers, lack of awareness of autonomous learning, lack of resources for autonomous learning, lack of guidance for autonomous learning, lack of ability to identify learning resources. In order to realize the autonomous learning of College Students under the mode of distance education, it is necessary to improve the consciousness and ability of autonomous learning of college students, improve the teaching skills and quality of teachers, set up autonomous learning guidance courses, develop high-quality autonomous learning resources, and improve the quality of autonomous learning of College students.
\end{abstract}

Keywords: distance education mode, independent learning, college students, teachers

\section{远程教育模式下大学生自主学习研究}

\author{
廖艺东 ${ }^{1 a}$, 赵剑华 $2 b$
}

12 江西师范大学，江西南昌，330022

'1021048916@qq.com, ${ }^{b} 190555223 @ q q . c o m$

*廖艺东

\section{摘要}

在当今社会背景环境下, 远程教育为大学生的自主学习提供了丰富的学习资源和便捷化的学习方式。 远程教育模式下, 大学生自主学习存在诸多问题, 如大学生对教师有较强的依赖性、缺乏自主学习的 意识、缺乏自主学习的资源、缺乏自主学习指导、缺乏鉴别学习资源的能力。实现远程教育模式下的 大学生自主学习, 应提高大学生的自主学习意识和能力, 提高教师的教学技能和素质, 开设自主学习 指导课程, 开发优质的自主学习资源, 进而提高大学生自主学习的质量。

关键词: 远程教育模式、自主学习、大学生、教师

\section{1. 相关概念的界定}

$$
\text { （一）远程教育 }
$$

现代远程教育，也称网络教育，它不同于函授教育形 式和广播电视教育形式, 是第三代远程教育形式。它是指 在教与学时空分离状态下, 师生凭借网络和多媒体技术, 充分利用优质的现代远程教育资源, 通过现代远程教育体 系保持双向联系, 并按一定模式进行交互教学的一种活动 [1]。它包括几个显著的特征: 教学过程中的师生是处于异 地的状态, 学生的学习是以自我导向为主的自主学习; 教
师和学校为学生提供学习辅助; 师生之间的交流通过 技术手段实现，教师和学生可以实现双向交流。

\section{(二) 自主学习}

从远程教育的角度来理解, 自主学习是指学习者 在教师的指导下, 依据一定的多媒体资源, 通过多种 途径, 自主获取信息、建构知识体系的过程, 在这个过 程中, 学习者自己制定学习计划, 自己决定学习内容 和进度, 自己选择学习方法和技巧, 自己安排和管理 时间, 自己控制和评价学习 ${ }^{[2]}$ 。我国学者庞维国认为自 主学习是在学生内在动机激发下产生的, 建立在学生 自我认识和自我了解的基础上, 运用一定学习策略实 现自我塑造、自我教养。 ${ }^{[3]}$ 福建师范大学余文森教授 
认为, 自主学习是一种学生占据主导地位, 充分发挥学生 自我教育潜能的一种学习方式。

\section{2. 远程教育模式下大学生自主学习存在的问 题}

\section{（一）大学生对教师有较强的依赖性}

在传统教育观念里, 知识赋予了教师神圣的地位, 教 师掌握着传授知识的权利, 学生只是教师教学活动的配合 者。长期以来 “以教师为中心” 的教学模式深深地扎根在 学生的头脑之中, 学生习惯于以教师为中心, 以教材为中 心, 习惯于一切围着教师转, 学生属于被动、机械地接受 学习。远程教育则强调以学生的自主学习为中心, 学生居 于主体地位, 教师居于引导、辅导、帮助地位, 中心的转 移, 使得很多学生不能适应。

(二) 大学生缺乏自主学习的意识

要培养大学生的自主学习能力, 最重要的是大学生要 具备较强的自制力跟自主学习的意识。只有大学生内心真 正渴望获得知识, 并且全身心投入对知识的探索中, 才能 实现自主学习。而大学生在面对现代远程教育环境下丰富 的学习资源和信息, 大学生没有充分利用好网络媒体开展 学习活动, 在网上许多游戏和各种娱乐资源的诱惑下, 大 学生的注意力很快就被吸引, 电脑、网络、手机等大多数 被用来休闲、娱乐, 如看影视剧、聊天、交友等, 出现这 种现象, 归根结底是因为大学生自主学习意识缺乏、自制 力较差, 没有抵制住来自网络和手机的诱惑, 最终导致学 习效果低下。

(三)大学生缺少优秀的自主学习资源和对资源的笁选 能力

现代远程教育资源丰富多样, 丰富多样的网络平台给 大学生提供了大量学习资源, 但由于部分教师专业能力不 强和职业素养较低, 致使网络学习资源不够丰富, 资源载 体单一、单调无味。有些网络资源均为文本、图片, 视频 资源较少, 学习平台一些网络资源实用性不强, 缺少具体 的专业学习方法和实践指导, 缺少案例分析、操作演示、 模拟实践、学习自测、学科拓展等, 不能吸引学习者利用 资源自主学习。其次在网络教育模式下, 大学生获取的资 源都是相对固定的, 可供专门针对自主学习的资源并不多。 另外, 网络课程和电子书籍是大学生远程教育模式下获取 知识的重要途径, 但是很多网络课程和电子书籍都需要收 取高昂的费用, 并且一些优秀作品并不对外开放, 学习资 源没有办法做到全民普及和全球开放。再者远程教育背景 下的网络媒体拥有广大的学习资源, 海量的信息充斥着大 学生的网络媒体设备, 其中必然存在着大量与自主学习无 关的信息。随着年龄的增长, 大学生对于信息的鉴别、筛 选能力有所提升, 但对于大量的不良信息, 大学生还不能 完全笁选和鉴别, 因此, 大学生可能会接触到一些落后的、 无用的学习资源, 造成经济的损失和学习精力的浪费, 大 学生很难在大量的资源中找到符合自己要求的学习资源。

（四）大学生缺乏自主学习指导

目前, 大学生在自主学习过程中缺乏科学的指导, 在 学习目标、学习方法、学习进度方面没有科学、合理的规
划, 学习中感觉无所适从。首先, 远程教育模式下, 教 师指导大学生开展自主学习会存在很多缺陷。由于很 多大学生是根据自己的时间学习网络课程的, 教学活 动与学习活动不能同步开展, 所以教师无法针对大学 生实施实时的指导。其次, 教师不但要引导大学生识 别自身的素质缺陷, 还要指导、帮助大学生制定自主 学习目标, 由于大学生个体之间存在差异, 因此教师 很难顾及全部大学生并实施 “一对一” 的指导。再者, 大学生自主学习能力的培养需要有相关课程的指导, 但是目前学校很少设置相关课程, 教学形式过于单调, 与大学生的互动不足。

\section{3. 远程教育模式下提升大学生自主学习能 力的实施策略}

(一) 转变传统教育观念, 树立自主学习的观念

大学生适应自主学习新模式的首要环节就是转 变传统教育观念, 转变观念是大学生提高自主学习能 力的关键, 只有真正实现了教育观念的转变, 才能使 得远程教育模式下的自主学习能够沿着健康的轨道 前行, 达到预期的目标。行主动选择、处理的过程中 完成的。 ${ }^{[4]}$ 因此, 在自主学习模式中首先要明确的就 是师生角色, 教师是引导、学员是主体, 要将各自的 作用在自主模式中得到充分的发挥。首先要强调学生 的主体地位, 调动学生的主动性, 让学生了解远程教 育下的教学和课程是互动的、交互式的和对话式的。 其次学生可以通过阅读文章，查找资料了解远程开放 教育的学习模式、开放教育的内涵, 转变思想, 建立 新的学习观念, 熟悉获取必要的教学资源和学习支持 服务的方式和途径, 明确自己在新的学习模式中所处 的地位, 即从求知的被动者转为求知的主动者。

（二）加强对大学生自主学习方法的指导

远程教育模式下自主学习以学生自学为主, 但并 不是完全意义上放任学生, 由学生漫无目的地自学。 第一, 需要教师针对学习者特定的特征对其学习方法 加以指导, 使学生明白自己需要学什么和怎么去学。 教师要帮助学生自身的特点为学生制定合理的学习 计划, 通过引导学生, 促使学生合理安排自己的时间, 利用各种手段进行自主学习。第二, 需要学校开设自 主学习指导课程, 引导大学生科学、合理地利用远程 教育平台和网络学习资源, 找到适合自己的学习方法, 提高自主学习能力。首先, 加强网络媒体知识的学习, 大学生对于网络媒体使用的认识方面大多在娱乐方 面, 对于如何利用网络媒体进行有效的学习并不是很 清楚。学校开设相关课程, 可以让大学生尽快适应远 程教育模式的教学, 提高自主学习的积极性、主动性 和适应性。其次, 加强大学生信息识别能力的培养。 网络信息虽然丰富多样, 但也参差不齐, 大学生要提 高信息处理能力, 甄别不健康信息, 迅速找到自己所 需信息, 避免沉迷于网络。再者, 要促进大学生自主 学习习惯的养成。即在远程教育模式下, 一方面要引 导大学生独立思考, 自己进行学习规划, 提高学习自 


\section{REFERENCES}

他们的学习方法, 使大学生少走弯路, 提高学习效率。

（三）扩宽大学生获取优质学习资源的途径

优质的学习资源是大学生自主学习得以顺利实现的 基本保障 ${ }^{[5]}$ 。教育资源的商业化, 各个学校的教育资源不 愿意公开等因素, 使得大学生缺少能够获得优质学习资源 的途径, 因此需要学校与老师的帮助。首先学校可以通过 与网络资源平台达成合作，减少学生在查找资源的费用; 对于其他学校或者国外的优秀学习资源, 学校要通过各种 渠道加以引进, 吸收国内外优秀教育资源, 充实到远程教 育资源体系中。其次需要教师开发针对大学生自主学习需 要的、有特色的学习资源, 教师可以通过录制视频或者制 作动画等形式呈现学习内容, 并将其上传到网络学习资源 平台。再者, 各个学校之间可以达成相互交流的合作, 在 彼此的网络资源平台中搭建一条通道, 使学生可以在各个 学校的资源平台中获取自己想要的自主学习资源。

(四) 教师引导学生做好学习过程监控和学习效果评 价

远程教育的教学模式不同于传统教育, 它利用现代信 息技术和网络媒体手段和工具, 为学生学习提供多种网络 课程资源和多种形式的教学活动, 提供以学生为中心的服 务, 整个学习过程以学生自主学习为主。在此过程中学习 中心和教师对学习者的学习过程监控和学习效果评价也 必不可少。为了要保证远程学习的质量, 对于学生的学习 质量监控和学习效果评价是必要环节。当然, 远程监控和 评价过程中不仅要考虑到远程教育的特点, 更要考虑到远 程自主学习者自身的特点。即其年龄、知识基础、技术水 平、学习目标、对于网络媒体的掌握程度和对于远程教育 模式下的自主学习的认可度不尽相同。而且他们普遍学业 和社团工作压力大, 学习时间有限。因此, 只有从学习者 实际出发, 对其提出 “既可望又可及” 的要求, 在评价上 确定清晰可行的标准, 才能使其易于接受。教学组织者要 合理安排课程辅导、小组讨论、网上答疑、在线测试等环 节, 要综合利用多种媒体资源进行教学辅导。增强教师角 色在网络学习过程中的参与程度, 在评价与监控过程中增 加教师的参与度, 发挥教师的主导作用, 帮助学生完成对 自身的评价和监控作用。在学习效果评价环节, 要注意评 价手段和角度的多元化, 评价要客观全面, 重视对整个学 习过程的评价, 重视学习者能力水平的提高, 切实保证评 价的结果正确无误, 从而提高大学生的自学能力。

\section{4. 总结}

由于各种因素的限制, 远程教育模式下大学生的自主 学习能力无法得到很好的提升, 但只要我们能够打破传统 教育观念, 树立以学生为主体的理念, 学校与教师帮助学 生采取有效的措施, 扩大学生获取资源的途径, 通过教师 引导大学生在自主学习道路上向正确的方向前进, 最终可 以使大学生的自主学习得到落实。
[1] Liu Fengcun. Research on adult students' autonomous learning in modern distance education environment [D]. Qufu Normal University. 2007

[2] Millie. On the strategies to improve the autonomous learning ability of distance education students [J]. Chinese Adult Education

[3] Zhong Qiquan. For the rejuvenation of the Chinese nation, for the development of each student. An interpretation of the outline of basic education curriculum reform (for Trial Implementation). Shanghai: East China Normal University Press. 2001

[4] Zhu Jun. teaching research of autonomous learning based on matrix and transformation [D]. Nanjing Normal University, 2009

[5] Cheng Xiuying. Problems and implementation strategies of College Students' Autonomous Learning under distance education mode. Education theory and practice [J]. 2018.18 